\title{
Toxicon
}

Toxicon 39 (2001) 1009-1019

www.elsevier.com/locate/toxicon

\section{Purification, amino-acid sequence and partial characterization of two toxins with anti-insect activity from the venom of the South American scorpion Tityus bahiensis (Buthidae)}

\author{
Adriano M. C. Pimenta ${ }^{\mathrm{a}, \mathrm{b}, *}$, Marie-France Martin-Eauclaire ${ }^{\mathrm{d}}$, Hervé Rochat $^{\mathrm{d}}$, \\ Suely G. Figueiredo ${ }^{\mathrm{e}}$, Evanguedes Kalapothakis ${ }^{\mathrm{b}}$, Luiz Carlos C. Afonso ${ }^{\mathrm{f}}$, \\ Maria Elena De Lima ${ }^{\mathrm{c}}$ \\ ${ }^{a}$ Departamento de Fisiologia e Biofísica, ICB, Universidade Federal de Minas Gerais, 31270-901, Belo Horizonte, MG, Brazil \\ ${ }^{\mathrm{b}}$ Departamento de Farmacologia, ICB, Universidade Federal de Minas Gerais, 31270-901, Belo Horizonte, MG, Brazil \\ ${ }^{\mathrm{c} D e p a r t a m e n t o ~ d e ~ B i o q u i ́ m i c a ~ e ~ I m u n o l o g i a, ~ I C B, ~ U n i v e r s i d a d e ~ F e d e r a l ~ d e ~ M i n a s ~ G e r a i s, ~ 31270-901, ~ B e l o ~ H o r i z o n t e, ~ M G, ~ B r a z i l ~}$ \\ dLaboratoire de Biochimie, Ingénierie des Protéines, UMR6560, IFR Jean Roche, 15, Bd Pierre Dramard, 13916, Marseille, France \\ ${ }^{\mathrm{e}}$ Departamento de Ciencias Fisiólogicas, CBM, Universidade Federal do Espirito Santo, Av. Marechal Campos 1468, 29040-090, \\ Vitória, ES, Brazil \\ ${ }^{\mathrm{f}}$ Laboratório de Imunoparasitologia DECBI/NUPEB-ICEB, Universidade Federal de Ouro Preto, 35400-000, Ouro Preto, MG, Brazil
}

Received 3 July 2000; accepted 31 October 2000

\begin{abstract}
We report here the isolation by a two-step chromatographic procedure of two new toxins from the South American scorpion Tityus bahiensis. Their amino-acid sequences and some of their biological features were established. The two toxins have different biological properties. Toxin TbIT-I had almost no activity or pharmacological effects in vertebrate tissues whereas it was lethal to house flies $\left(\mathrm{LD}_{50} 80.0 \mathrm{ng} /\right.$ house fly). In contrast, Tb2-II was active against both mammals (intracerebroventricular injection of $100 \mathrm{ng} /$ mouse was lethal) and insects $\left(\mathrm{LD}_{50} 40.0 \mathrm{ng} /\right.$ house fly). The amino-acid sequences of these toxins were established and found to be similar (60-95\%) to previously described $\beta$-toxins from the Tityus genus. Based on the available comparative information, this study attempts identify possible structure-function relationships that may be responsible for the differences in bioactivity displayed by these toxins. () 2001 Published by Elsevier Science Ltd.
\end{abstract}

Keywords: Tityus bahiensis; Toxin; Anti-insect activity; Three-dimensional models

\section{Introduction}

Arthropod toxins are used in an enormous variety of approaches and interdisciplinary studies. Their biological properties and proteinaceous nature render them of use in many fields. The possibility of using proteinaceous toxins and hormones highly active against insect crop pests, as a

\footnotetext{
* Corresponding author. Fax: +33-4-91-69-88-39.

E-mail address: pimenta.a@jean-roche.univ-mrs.fr (A.M.C. Pimenta).

Abbreviations: TbIT-I, Tityus bahiensis Insect Toxin I; Tb2-II, Tityus bahiensis Toxin 2-II; Tityus spp, species from Tityus genus; $\mathrm{LD}_{50}$, concentration giving half-maximal lethality
}

means of strengthening biological control, was first suggested early in the 1990s (Maeda et al., 1991; McCutchen et al., 1991; Stewart et al., 1991; Tomalski and Miller, 1991; Hammock et al., 1993). Since then, the search for molecules that could be engineered for applied use has considerably intensified.

Once their structures have been determined, scorpion neurotoxins with similar sequences but different binding properties can be used as powerful tools for probing the structural aspects of toxin-receptor interactions (Lebreton et al., 1994; Gordon et al., 1996; Selisko et al., 1996; Zilberberg et al., 1997; Jablonsky et al., 1999; Pintar et al., 1999; Polikarpov et al., 1999). The first scorpion neurotoxins to be studied were discovered due to their 
lethal effects on mammals. They act on voltage-gated sodium channels. The site at which they interact determines the physiological response in terms of excitatory currents. The $\alpha$-toxins bind to site 3, causing inactivation of the channel. The $\beta$-toxins, on the other hand, bind to site 4 and increase the activation phase of $\mathrm{Na}^{+}$channels. These neurotoxins also have different effects on vertebrate and arthropod tissues, which has led to their classification according to toxicological spectrum, as anti-mammal, anti-insect and anti-crustacean toxins (for review see De Lima and Martin-Eauclaire, 1995).

Tityus bahiensis, together with Tityus serrulatus, is considered as one of the most dangerous species for humans in Brazil, and are responsible for many clinical cases of envenomation in the southern and northern regions of this country. T. serrulatus is better adapted to human habitats and, due its parthenogenetic strategy, has an increased reproduction rate when compared to T. bahiensis. This ecological competition has led to a decrease in $T$. bahiensis populations and, therefore, in clinical cases involving this species (Lourenço et al., 1996; Von Eickstedt et al., 1996).

A deep characterization of T. bahiensis venom, however, is still lacking. In spite of ecological and life history differences, the venoms of the two species seem to be very similar in their protein content and pharmacological characteristics (De Lima and Martin-Eauclaire, 1995; Becerril et al., 1996; Becerril et al., 1997). Both $\alpha$ and $\beta$ type toxins have been found in the venom of South American scorpions of the Tityus genus and toxins with high levels of sequence identity have been isolated from the venoms of $T$. serrulatus, $T$. bahiensis, and T. stigmurus (Becerril et al., 1996; for review see also De Lima and Martin-Eauclaire, 1995; Becerril et al., 1997).

Some highly homologous toxins from Tityus species (Tityus spp) display very specific bioactivity profiles. TsVII (Bechis et al., 1984; or $\gamma$-toxin in Possani et al., 1977) binds with high affinity to both mammalian and insect sodium channels (De Lima et al., 1986). The non-toxic TsNTxP has immunological properties in common with other toxins from Tityus spp venom but is not toxic and can therefore be used to develop immunization procedures (Chavez-Olórtegui et al., 1996; Chavez-Olórtegui et al., 1997).

The isolation and the sequences of two new toxins from $T$. bahiensis venom with anti-insect activity, are reported in this paper. Three-dimensional models were generated and the electrostatic charge distribution on the surface of molecules were calculated, in order to identify the residues responsible for selectivity for the insect sodium channel.

Determination of the molecular basis of toxin selectivity is crucial for elucidation of the interaction between toxins and their targets (i.e. the insect voltage-gated $\mathrm{Na}^{+}$channel). However, in addition to their usefulness in studies of toxin/ channel interaction events, these very similar toxins can also be used to design new bioinsecticides.

\section{Materials and methods}

\subsection{Animals and venom extraction}

Specimens of T. bahiensis were collected near Ouro Preto in the state of Minas Gerais in the Southern Region of Brazil. They were kept in plastic boxes and fed with crickets or cockroaches and water ad libitum until 15 days before venom extraction. The venom was extracted electrically, lyophilized and kept frozen $\left(-20^{\circ} \mathrm{C}\right)$ until use.

\subsection{Venom fractionation and toxin purification}

The lyophilized venom was solubilized in $0.15 \mathrm{M}$ ammonium formate $(\mathrm{pH}$ 6.3) and centrifuged at $15,000 \mathrm{rpm}$ (Marathon $13 \mathrm{~K} / \mathrm{H}$; Fischer Scientifics ${ }^{\circledR}$ ) at $4^{\circ} \mathrm{C}$ for $30 \mathrm{~min}$. The supernatant was then recentrifuged. The soluble fraction was loaded (10 $\mathrm{mg}$ maximum each run) onto a Superdex ${ }^{\circledR} 75$ HR 10/30 (Pharmacia ${ }^{\circledR}$ ) FPLC size exclusion column equilibrated and eluted with $0.15 \mathrm{M}$ ammonium formate $(\mathrm{pH} 6.3)$ at a flow rate of $0.25 \mathrm{ml} / \mathrm{min}$, at room temperature. The absorbance at $280 \mathrm{~nm}$ of the eluates was determined and the collected fractions $(0.5 \mathrm{ml}$ each $)$ were lyophilized twice and kept frozen $\left(-20^{\circ} \mathrm{C}\right)$ until use. The fractions of interest were further purified by reversephase HPLC on a Pico-Tag ${ }^{\circledR}$ column (Millipore ${ }^{\circledR}$ ). The samples were solubilized in $0.1 \%$ trifluoroacetic acid (TFA) in water the proteins were eluted in a linear gradient of $0.1 \%$ trifluoroacetic acid (TFA) in water to $0.1 \%$ TFA in acetonitrile. The flow rate was $1.0 \mathrm{ml} / \mathrm{min}$ and elution was monitored by measuring absorbance at $214 \mathrm{~nm}$. The fractions were collected manually, lyophilized and stored until required.

\subsection{Electrophoresis}

Electrophoresis was performed using the tricine/SDSPAGE method described by Shagger and Von Jagow (1987) and the urea/propionic acid method described by Chettibi and Lawrence (1989).

\subsection{Amino-acid analysis}

Protein samples ( $1 \mathrm{nmol})$ were hydrolyzed under vacuum in a Pico-Tag ${ }^{\circledR}$ work station (Millipore/Water Associates ${ }^{\circledR}$ ) with $6 \mathrm{M} \mathrm{HCl}$ at $110^{\circ} \mathrm{C}$ for 20 or $70 \mathrm{~h}$. Phenol (1\%) was added to the acidic solution before hydrolysis to improve the recovery of tyrosine residues. The amino-acid composition of the proteins was determined using a Beckman 6300 apparatus as previously described (Céard et al., 1992).

\subsection{Amino-acid sequencing}

Native and S-pyridylethylated proteins were sequenced using an Applied Biosystems ${ }^{\circledR}$ 476A sequencer. Toxin $(5 \mathrm{nmol})$ was reduced and alkylated as previously described (Friedman et al., 1970) and desalted on a narrow-bore 
system from Applied Biosystems $®$ (140A Solvent Delivery System and 759A Absorbance Detector) equipped with a C8 column (Brownlee RP300, $7 \mu \mathrm{m}, 2.1 \times 220 \mathrm{~mm}$ ). Absorbance was measured at $214 \mathrm{~nm}$.

\subsection{Mass spectrometry}

MALDI-TOF (Matrix-Assisted Laser Desorption Ionization - Time Of Flight) analysis was performed on a Voyager-DE ${ }^{\mathrm{TM}} \mathrm{RP}$ BioSpectrometer Workstation (Perseptive Biosystems ${ }^{\circledR}$ ) in the linear mode. The drieddrop method was used for sample preparation. A volume of $0.5 \mu \mathrm{l}$ of protein solution $(1.0 \mathrm{pmole} / \mu \mathrm{l})$ was spotted on the target, followed by $0.5 \mu$ l of matrix CHCA $(\alpha-$ cyano-4-hydroxycinnamic acid) solution and dried at room temperature. A $337 \mathrm{~nm}$ nitrogen laser was used to desorb the samples.

\subsection{Preparation of antibodies and enzyme-linked immunosorbent assay (ELISA)}

ELISA assays were carried out as previously described (Kalapothakis and Chavez-Olórtegui, 1997). Plates (96well plates, Hemobag, Produtos Cirúrgicos, Campinas, $\mathrm{SP}$, Brazil) were coated overnight at $4^{\circ} \mathrm{C}$ or for $3 \mathrm{~h}$ at room temperature with $100 \mu \mathrm{l} /$ well of coating buffer (carbonate buffer, $\mathrm{pH}$ 9.6) supplemented with 350 or $700 \mathrm{ng}$ of the toxin tested. Assays were conducted as described by Chavez-Olórtegui et al. (1991) and absorbance was measured at $492 \mathrm{~nm}$ with a Titertek Multiscan plate spectrophotometer. All measurements were made in duplicate. Antisera were raised as described by Kalapothakis and Chavez-Olórtegui (1997) using TsFG50 (toxic Sephadex G50 fraction of T. serrulatus venom; Chavez-Olórtegui et al., 1997), and toxins TsIV ( $\alpha$ toxin) and TsVII ( $\beta$ toxin), purified from $T$. serrulatus venom according to published procedures (Possani et al., 1981; Bechis et al., 1984).

\subsection{Toxicity tests}

The toxicity of fractions and pure toxins was assayed using house flies (Musca domestica, DIPTERA; adults weighing $20.0 \pm 2.0 \mathrm{mg}$ ), common crickets (Acheta domestica, ORTHOPTERA; nymphs weighing $100.0 \pm 10.0 \mathrm{mg})$, common cockroaches (Periplaneta americana, DICTYOPTERA; nymphs weighing $100.0 \pm 10.0 \mathrm{mg}$ ) and albino mice (weighing $20.0 \pm 2.0 \mathrm{~g}$ ). The insects were chilled for $5 \mathrm{~min}$ at $4^{\circ} \mathrm{C}$ and then the toxins were injected into the thoracic cavity. Toxins were administered to mice by intracerebroventricular (icv) injection, as described by Rezende et al. (1991). Controls were injected with $0.25 \mathrm{mg} / \mathrm{ml}$ bovine serum albumin (BSA) in saline. The following signs of toxicity were assessed: excitability, salivation, trembling of the legs and body, jerking of the limbs, knot-out, loss of ability to walk or fly and death.

\subsection{Computer analysis}

Sequences identity were obtained using ADVANCED BLAST SEARCH in the NCBI Web page (http:// www.ncbi.nlm.nih.gov/BLAST).

\subsection{Molecular modeling}

TbIT-I and Tb2-II models were built by homology modeling using MODELLER-3 (Sali and Blundell, 1993) based on the crystallographic structure of Ts1 (Polikarpov et al., 1999) deposited in the Brookhaven Protein Data Bank (accession code 1b7d). The stereochemistry of the models was checked with PROCHECK-3 (Laskowski et al., 1993). The electrostatic potential of surfaces and the net charge of molecules were calculated using GRASP software (Nicholls et al., 1991). For TbIT-I models, the last residue in the sequence, established as B (Asx), was omitted.

\section{Results}

\subsection{Purification of toxins and assessment of their bioactivity}

The fractionation of $T$. bahiensis venom by FPLC gel filtration resulted in seven main pools, S1-S7 (Fig. 1(A)). When screened with high doses into mice $(1.0 \mu \mathrm{g} / \mathrm{mouse}$, icv), fractions S1, S5 and S7 were lethal whereas the other fractions gave various toxicological signs (Table 1). Fractions were tested $(2.5-8.3 \mathrm{ng})$ on insects from three orders: DIPTERA ( $M$. domestica), ORTHOPTERA (A. domestica) and DICTYOPTERA (P. americana). Activity at given doses (mg/body weight) was compared for the three species and house flies were found to be the most sensitive (Table 1).

Fractions S6 and S7 were purified further. Electrophoresis (SDS/tricine and urea/propionic acid) of these fractions indicated weak contamination (Fig. 1, inset). Further purification RP-HPLC (Pico-Tag ${ }^{\circledR}$ column) was undertaken, and two proteins, TbIT-I and Tb2-II, were obtained, from S6 and S7, respectively (Fig. 1(B) and (C)).

Mice recovered within a few hours of icv injection of a large dose of TbIT-I $(10.0 \mu \mathrm{g})$, with only weak signs of envenomation observed. In contrast, the $\mathrm{LD}_{50}$ of this toxin in house flies was found to be $80.0 \mathrm{ng} /$ house fly $(4.0 \mathrm{ng} / \mathrm{mg}$ of body weight). Tb2-II was also found to be lethal for house flies ( $\mathrm{LD}_{50} 40.0 \mathrm{ng} /$ house fly; $2.0 \mathrm{ng} / \mathrm{mg}$ of body weight) and mice (lethal at $100 \mathrm{ng} /$ mouse by icv injection).

\subsection{Biochemical characterization of toxins}

The amino-acid compositions of both proteins were determined (Table 2). Fig. 2 shows the complete amino-acid sequences of TbIT-I and Tb2-II, as determined by automated Edman degradation. The proteins are 63 (TbIT-I) and 62 (Tb2-II) amino acids long and the repetitive yields in sequencing procedures were more than $93 \%$ for residues 

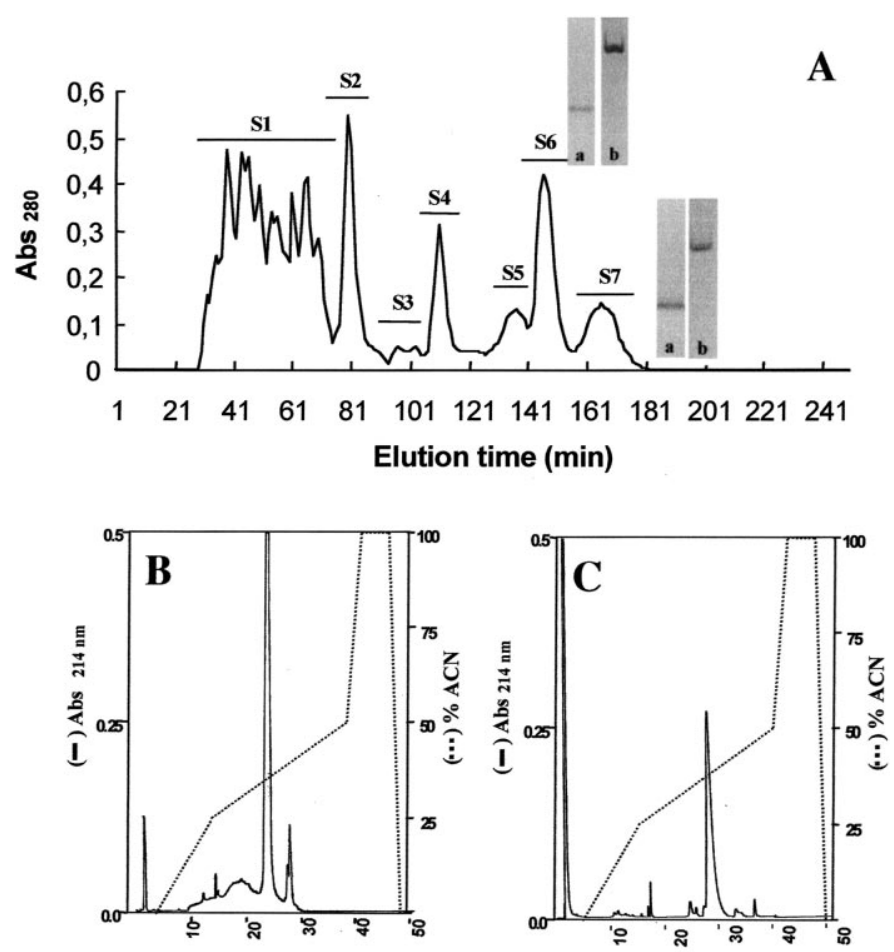

\section{Elution time ( $\mathrm{min})$}

Fig. 1. Gel filtration of T. bahiensis venom using FPLC system. (A) The soluble fraction of T. bahiensis venom (10 mg each run) was loaded onto a Superdex 75 HR 10/30 column, equilibrated with $0.15 \mathrm{M}$ ammonium formiate, $\mathrm{pH}$ 6.3. The proteins were eluted with the same buffer, at a flow rate of $0.25 \mathrm{ml} / \mathrm{min}$. The fraction volume was $0.5 \mathrm{ml}$. Fractions yielded by this step were named $\mathrm{S} 1-\mathrm{S} 7$ (as indicated in the figure). Inset: (a) and (b) are, respectively, tricine-PAGE and urea-propionic acid-PAGE of the S6 and S7 fractions. (B) and (C): Reverse phase HPLC of fractions S6 and S7. A maximum of $600 \mu \mathrm{g}$ of the fraction was applied to a Pico-Tag C18 reverse-phase column equilibrated with $0.1 \%$ TFA in water. The elution was carried out by a linear gradient of $0.1 \%$ TFA in 0 to $100 \%$ acetonitrile. The flow rate was $1.0 \mathrm{ml} / \mathrm{min}$ and absorbance at $214 \mathrm{~nm}$ was determined. Fractions were collected manually.

Table 1

Toxicological profile of gel filtration fractions and of purified toxins from T. bahiensis venom (Toxic (T): $<50 \%$ of injected animals dead, but all showing signs of poisoning; Lethal (L): $>50 \%$ of injected animals dead; NT: nontoxic, at the dose indicated. Dead animals were counted after 24 h. Nd: not determined)

\begin{tabular}{lllll}
\hline Fraction/toxin & Mice $^{\mathrm{a}}(n=2)$ & House flies $^{\mathrm{b}}(n=12)$ & Crickets $^{\mathrm{c}}(n=3)$ & Cockroaches $^{\mathrm{c}}(n=3)$ \\
\hline S1 & $\mathrm{L}$ & $\mathrm{L}$ & $\mathrm{T}$ & $\mathrm{T}$ \\
S2 & $\mathrm{T}$ & $\mathrm{T}$ & $\mathrm{NT}$ & $\mathrm{Nd}$ \\
S3 & $\mathrm{T}$ & $\mathrm{L}$ & $\mathrm{T}$ & $\mathrm{Nd}$ \\
S4 & $\mathrm{T}$ & $\mathrm{NT}$ & $\mathrm{Nd}$ \\
S5 & $\mathrm{T}$ & $\mathrm{T}$ & $\mathrm{T}$ & $\mathrm{T}$ \\
S6 & $\mathrm{L}$ & $\mathrm{T}$ & $\mathrm{T}$ & $\mathrm{T}$ \\
S7 & $\mathrm{T}$ & $\mathrm{T}$ & $\mathrm{T}$ & \\
\hline
\end{tabular}

\footnotetext{
${ }^{\text {a }}$ Screening using $1.0 \mu \mathrm{g} / \mathrm{mouse}$ by icv injection.

b Screening using $2.5 \mathrm{ng} / \mathrm{mg}$ of body weight.

${ }^{c}$ Screening using $8.3 \mathrm{ng} / \mathrm{mg}$ of body weight.
} 


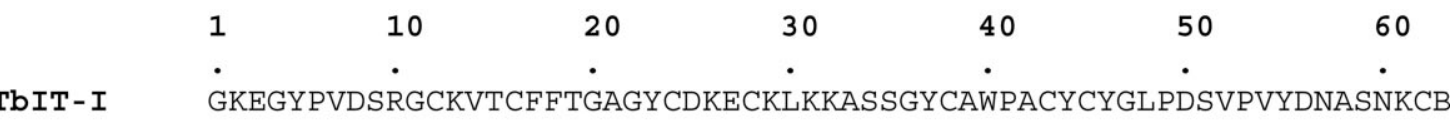

Fig. 2. Amino acid sequence of TbIT-I and Tb2-II, obtained by automated Edman degradation. (-) indicates sequencing of native toxin and (*) indicates sequencing of reduced and S-pyridylethylated toxin.

such $\mathrm{G}, \mathrm{K}$ and $\mathrm{Y}$. The last residue of TbIT-I was established as Asx (or B, in the one-letter code). TbIT-I lacks M, H and I residues. This feature was used as an aditional criterion for assessing purity. Mass spectrometry showed a single peak for each toxin with a molecular weight of 6813.34 for TbITI and 6953.73 for Tb2-II (data not shown). These results are

Table 2

Amino-acid sequence analysis of TbIT-I and Tb2-II (nd, not determined; MM (calc), molecular mass calculated from amino acid sequence; $\mathrm{E} \mu \mathrm{M}\left(\mathrm{A}_{280 \mathrm{~nm}}\right)$, molar extinction coefficient; $\mathrm{A}_{280}$, absorbance at $280 \mathrm{~nm}$

\begin{tabular}{|c|c|c|c|c|}
\hline \multirow[t]{2}{*}{ Amino acid } & \multicolumn{2}{|l|}{ TbIT-I } & \multicolumn{2}{|l|}{$\mathrm{Tb} 2-\mathrm{II}$} \\
\hline & Analysis & Sequence & Analysis & Sequence \\
\hline Ala (A) & 5.2 & 5 & 5.2 & 5 \\
\hline $\operatorname{Arg}(\mathrm{R})$ & 1.0 & 1 & 0.8 & 1 \\
\hline Asn $(\mathrm{N})$ & nd & 3 & nd & 2 \\
\hline Asp (D) & 7.1 & 4 & 5.1 & 3 \\
\hline Cys (C) & 3.9 & 8 & 3.3 & 8 \\
\hline Gln (Q) & nd & 0 & nd & 0 \\
\hline Glu (E) & 2.1 & 2 & 2.4 & 2 \\
\hline Gly (G) & 7.1 & 7 & 6.5 & 6 \\
\hline His $(\mathrm{H})$ & 0.0 & 0 & 1.8 & 2 \\
\hline Ile (I) & 0.0 & 0 & 1.5 & 2 \\
\hline Leu $(\mathrm{L})$ & 2.0 & 2 & 1.2 & 1 \\
\hline Lys (K) & 6.9 & 7 & 5.5 & 6 \\
\hline Met (M) & 0.0 & 0 & 0.9 & 1 \\
\hline Phe (F) & 2.0 & 2 & 2.6 & 3 \\
\hline Pro $(\mathrm{P})$ & 4.2 & 4 & 3.0 & 3 \\
\hline $\operatorname{Ser}(S)$ & 4.6 & 5 & 4.7 & 5 \\
\hline Thr (T) & 2.0 & 2 & 1.9 & 2 \\
\hline $\operatorname{Trp}(\mathrm{W})$ & nd & 1 & nd & 2 \\
\hline Tyr (Y) & 5.6 & 6 & 5.0 & 6 \\
\hline Val (V) & 3.8 & 4 & 1.7 & 2 \\
\hline Total residues & 58 & 63 & 55 & 62 \\
\hline $\mathrm{MM}_{(\mathrm{calc})}$ & \multicolumn{2}{|c|}{$6813.72 \pm 1.0 \mathrm{Da}^{\mathrm{a}}$} & \multicolumn{2}{|c|}{$6955.95 \mathrm{Da}$} \\
\hline MALDI-TOF & \multicolumn{2}{|c|}{$6813.34 \mathrm{Da}$} & \multicolumn{2}{|c|}{$6953.73 \mathrm{Da}$} \\
\hline $\mathrm{E} \mu \mathrm{M}\left(\mathrm{A}_{280 \mathrm{~nm}}\right)$ & \multicolumn{2}{|c|}{13.850} & \multicolumn{2}{|c|}{19.540} \\
\hline $\mathrm{A}_{280 \mathrm{~nm}}(0.1 \%)$ & \multicolumn{2}{|l|}{2.031} & \multicolumn{2}{|l|}{2.806} \\
\hline
\end{tabular}

${ }^{\text {a }}$ Difference between $\mathrm{N}$ and $\mathrm{D}$ masses. consistent with the theoretical masses calculated from the primary structures: $6813.72 \pm 1.0 \mathrm{Da}$ for TbIT-I and 6955.95 Da for Tb2-II (Table 2).

\subsection{Biological assays}

The toxins were immunologically characterized by ELISA using anti-TsFG50 (toxic fraction of T. serrulatus venom filtered through Sephadex G50), anti-TsIV ( $\alpha$ toxin) and anti-TsVII ( $\beta$ toxin) antibodies (Fig. 3). Both TbIT-I and Tb2-II cross-reacted with anti-TsFG50 and anti-TsVII antibodies. No cross reaction was observed with anti-TsIV antibodies. Thus, the molecules belong to the same immunological group as the $\beta$-toxins purified from $T$. serrulatus venom (Fig. 3).

Binding experiments (data not shown) showed that neither TbIT-I nor Tb2-II displaced the $\alpha$-toxin, AaII (Androctonus australis toxin II), from its binding site in rat brain synaptosomal preparations. TbIT-I was also unable to compete with the $\beta$-toxin, TsVII, in the same preparation. In contrast, $10^{-7} \mathrm{M}$ Tb2-II displaced $53 \%$ of ${ }^{125} \mathrm{I}$-CssII binding in rat brain synaptosomes (data not shown), and thus this toxin may be considered to be a $\beta$-toxin, from a pharmacological point of view. These biological results are consistent with the amino-acid sequences obtained by Edman degradation, which showed that the two toxins belong to the $\beta$-toxin family, on the basis of sequence similarity.

\section{Discussion}

\subsection{Sequence similarity between Tityus toxins}

Becerril et al. (1997) classified long-chain Tityus toxins into five groups, according to their sequence similarities and pharmacological properties. Indeed, although the nomenclature of these toxins is somewhat confusing, it is clear that they can be clustered together into groups of proteins with similar biological and biochemical properties. Comparison of the sequences of proteins from a single group, or from different groups, may provide insight into the role of certain 

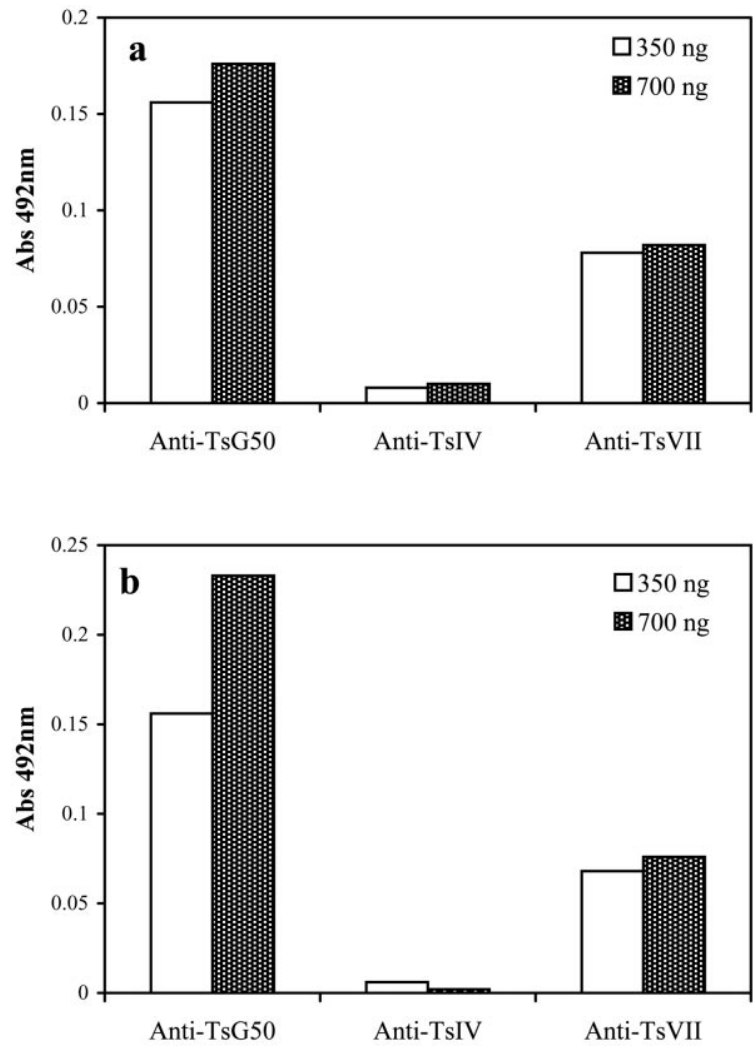

Fig. 3. Immunological identification of TbIT-I and Tb2-II by antibodies against Tityus serrulatus toxins. ELISA plates (Hemobag, Campinas, Brazil) were incubated with $100 \mu \mathrm{l} /$ well of sodium carbonate buffer, $\mathrm{pH} 9.6$ containing 350 or $700 \mathrm{ng}$ of TbIT-I (a) or Tb2-II (b) for $12 \mathrm{~h}$ at $4^{\circ} \mathrm{C}$. Anti-TsG50 (1:1000), anti-TsIV $(1: 1500)$ and anti-TsVII $(1: 2000)$ rabit serum were used. For details, see Materials and Methods.

key residues in Tityus toxins. This, in turn, may help us to determine why some of these toxins have different effects on mammalian and insect nervous systems, despite having very similar sequences.

The sequences of TbIT-I and Tb2-II are very similar to those previously reported for toxins from the genus Tityus (Fig. 4). The sequence of TbIT-I is $72 \%$ identical to that of the TsNTxP protein of $T$. serrulatus (Chaves-Olórtegui et al., 1996) and 70\% identical to that of T. serrulatus TsTXVI (Marangoni et al., 1990). These two proteins from T. serrulatus are known to be nontoxic to mice (Marangoni et al., 1990; Chaves-Olórtegui et al., 1996). The sequence of TbIT-I is also very similar to the N-terminal sequence of Tb4 (GKEGYPTDKRGCLTCFFT) from $T$. bahiensis published by Becerril et al. (1996). Tb4 also displayed no toxic activity in mice and its full sequence was therefore not determined. The sequence of TbIT-I is also $67 \%$ identical to that of TsVII (Bechis et al., 1984; or Ts $\gamma$ from Possani et al., 1977; or Ts1 from Becerril et al., 1996; Becerril et al., 1997;
Polikarpov et al., 1999), the most studied toxin of T. serrulatus venom.

The sequence of $\mathrm{Tb} 2-\mathrm{II}$ is $96 \%$ identical to that of $\mathrm{Tb} 2$ from T. bahiensis (Becerril et al., 1996), and 95\% identical to those of TsII, from T. serrulatus (Mansuelle et al., 1992), and Tst2, from T. stigmurus (Becerril et al., 1996). The sequence of $\mathrm{Tb} 2-\mathrm{II}$ is also $75 \%$ identical to that of TsVII (Bechis et al., 1984; or Ts $\gamma$ from Possani et al., 1977; or Ts1 from Becerril et al., 1996; Becerril et al., 1997; Polikarpov et al., 1999). Despite their very similar sequences, Tb2-II and TsII differ in biological activity. Tb2-II was lethal for house flies, ( $\mathrm{LD}_{50} 40.0 \mathrm{ng} /$ house fly) whereas TsII was considered to be nontoxic when injected into blowfly larvae (Sarcophaga argirostoma) (De Lima et al., 1986). Furthermore, Tb2-II was recognized by anti-TsVII antibodies in ELISA, whereas TsII was assigned to another immunological subfamily on the basis of radioimmunoassay (RIA) experiments (Mansuelle et al., 1992). However, as the immunological (ELISA and RIA) and biological (adult house flies and blowfly larvae) assays used have different sensitivities further comparative studies, using TsII and Tb2-II, are needed to quantify and characterize the biological differences between these two toxins.

These results concerning sequences and bioactivity raise two main questions: (i) What are the major differences that result in a higher level of activity against insects? (ii) Why do some toxins have dual high activity (e.g. TsVII and Tb2II) whereas others, with very similar sequences do not (as shown for TsII and Tb2-II)?

Analysis of the primary structures of fully sequenced long toxins from Tityus (Fig. 4) shows that some amino acid changes may affect the biological activity of TbIT-I and Tb2-II. The crystal structure of Ts1 (or Ts $\gamma$ from Possani et al., 1977; or TsVII from Bechis et al., 1984) was determined at a resolution of $1.7 \AA$ (Polikarpov et al., 1999). This toxin binds in both insect and mammalian tissues, with picomolar affinity (De Lima et al., 1986). This, and the high level of sequence similarity led us to use the threedimensional structure of TsVII as the basis for all comparison analysis. Residues important for TsVII bioactivity have been identified (Possani et al., 1985; Hassani et al., 1999; Polikarpov et al., 1999) and some interesting differences have been found at the equivalent positions in other toxins.

\subsection{Differences in the primary structures of toxins}

One of most curious differences in primary structure of these toxins is that at position 1. As shown in Fig. 4, the first residue is $\mathrm{K}$ in all known $\alpha$ and $\beta$ toxins of Tityus spp, except those classified as nontoxic and Tst1, a gamma-like toxin from T. stigmurus (Becerril et al., 1996). In these proteins, the initial residue is an extra $G$, with the $K$ displaced to the second position. K1 may play an important role in toxin/channel recognition and binding due to: (i) the basic nature of this residue, which helps to create a positively charged surface, or (ii) the structural role played by 


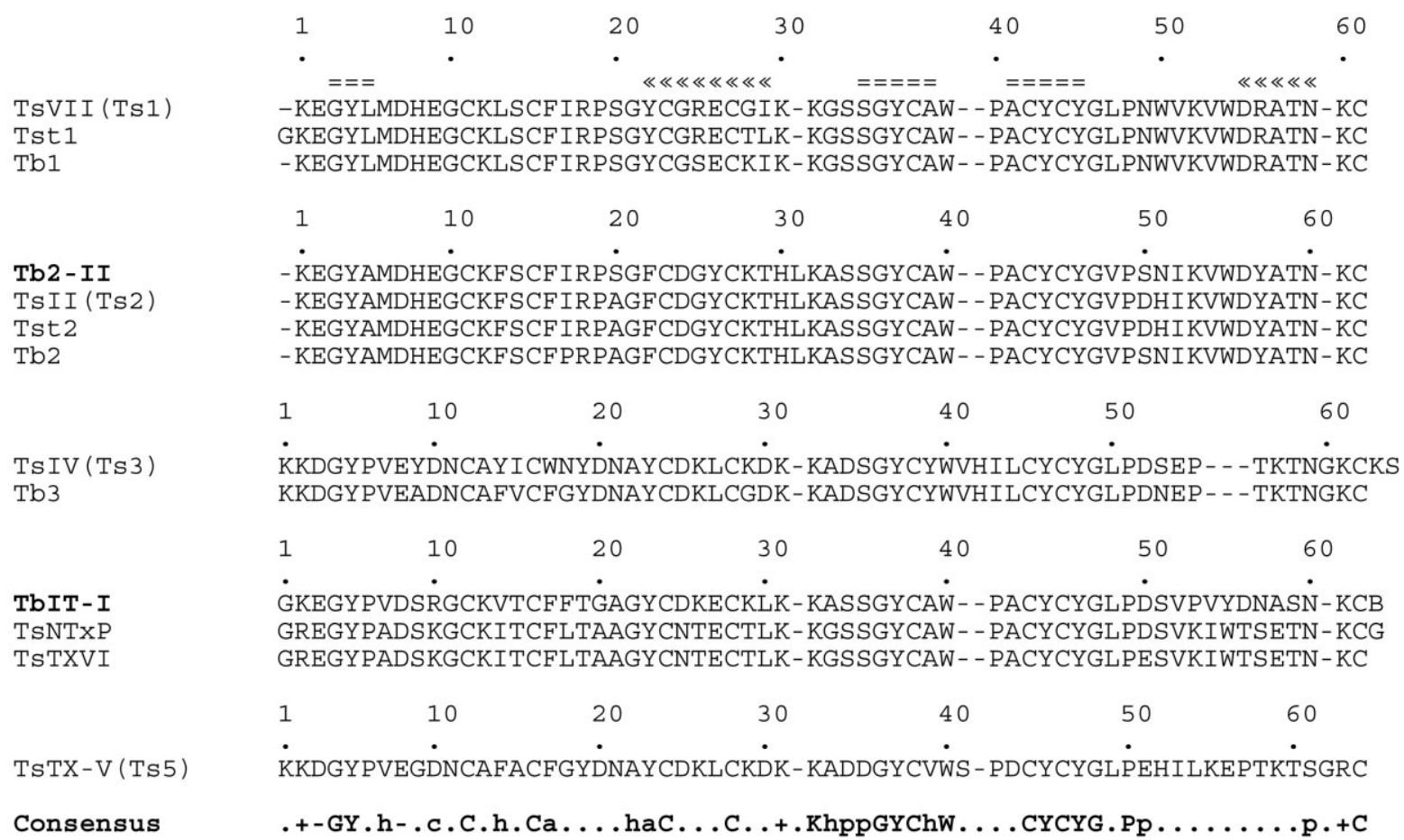

Fig. 4. Sequence similarity between Tityus toxins. Ts: Tityus serrulatus; Tb: T. bahiensis; Tst: T. stigmurus. Residues are represented in the oneletter code. (-) indicates gap due to insertion or deletion. B indicates Asx. TsVII (Possani et al., 1991; Martin-Eauclaire et al., 1992); TsNTxP (Chavez-Olórtegui et al., 1996); TsTXVI (Marangoni et al., 1990); TsIV (Possani et al., 1991; Martin-Eauclaire et al., 1994); TsTX5 (Marangoni et al., 1995) and Tb1, Tb2, Tb3, Tst1, Tst2 (Becerril et al., 1996). Secondary structures in TsVII (Polikarpov et al., 1999) are $(=)$ anti-parallel $\beta$-sheets and $(\ll \ll) \alpha$-helices. Consensus simbols: $(+)$ indicates positively charged residue consensus; $(-)$ indicates negatively charged residue consensus; $h$ indicates hydrophobic residue consensus; $c$ indicates charged residue consensus; a indicates aromatic residue consensus and $\mathrm{p}$ indicates polar residue consensus. Numbering indicates the residues position in the sequence for each group.

this residue since its $\epsilon$-amino group, which forms two hydrogen bonds with residues $\mathrm{N} 49$ and V51, is involved in Cterminal loop stabilization (Policarpov et al., 1999). An initial residue with different charge and polarity features might disrupt the function of $\mathrm{K} 1$, resulting in a lower level of toxicity. Despite the differences at these two positions in TsVII, TbIT-I and Tb2-II, in both the TbIT-I and Tb2-II models hydrogen bonds were found connecting the C-terminus to the initial residues. Tst1, which has a G1 residue and a sequence $95 \%$ identical to that of the highly toxic TsVII, has been reported to be toxic, and not lethal, to mice (Becerril et al., 1996). This protein has not been characterized further either toxicologically or pharmacologically.

In TbIT-I, a P6V7 segment replaces the L5M6 of TsVII. Although this segment is buried within the protein, residue M6 is highly conserved in $\beta$-toxins from Tityus spp whereas the P6V7 segment is found in Tityus $\alpha$-toxins (Fig. 4).

An important change that may be responsible for the lack of mammal toxicity is found in both nontoxic proteins and TbIT-I. A positive residue, $\mathrm{R}$ in TbIT-I and $\mathrm{K}$ in TsNTxP and TsTX-VI, is found at position 10 (Marangoni et al., 1990; Chaves-Olórtegui et al., 1996), instead of the highly conserved negative residue in the equivalent position in $\alpha$-toxins (D10) and $\beta$-toxins (E9) from Tityus spp (Figs. 4 and 5).

A region comprising $\mathrm{C} 15-\mathrm{G} 21$ forms a loop in the structure of TsVII (Policarpov et al., 1999), which is found to be a variable segment between the groups of Tityus spp sequences (Fig. 4). Residues in this region have also been identified as being very important for recognition and the modulation of binding of scorpion toxins in arthropod $\mathrm{Na}^{+}$ channels (Selisko et al., 1996). This loop in TbIT-I is very different from those of TsVII and Tb2-II, with two consecutive $\mathrm{F}$ residues $(\mathrm{F} 17 \mathrm{~F} 18)$ and no positive R18. Also, one of the three differences between Tb2-II and TsII concerns position 20, which is occupied by a S residue in Tb2-II (Fig. 4).

In the structure of TsVII (Polikarpov et al., 1999), the $\alpha-$ helix is defined by residues Y22-I29, whereas residues K30-S33 form a loop that links the helix to the second $\beta$ sheet (defined by residues S34-A38). Y22 is replaced by another aromatic (F22) in Tb2-II whereas G24 is replaced by a negatively charged D in both Tb2-II and TbIT-I. Position 25, which is occupied by a R in TsVII and Tst1, is highly variable between Tityus spp toxins (Fig. 4).

Residues W39 and W54, together with K12, have been 


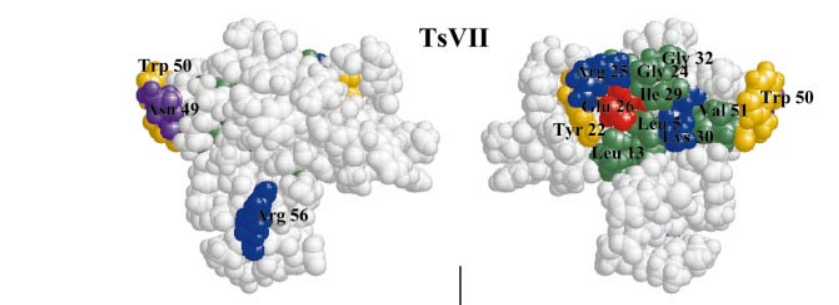

A
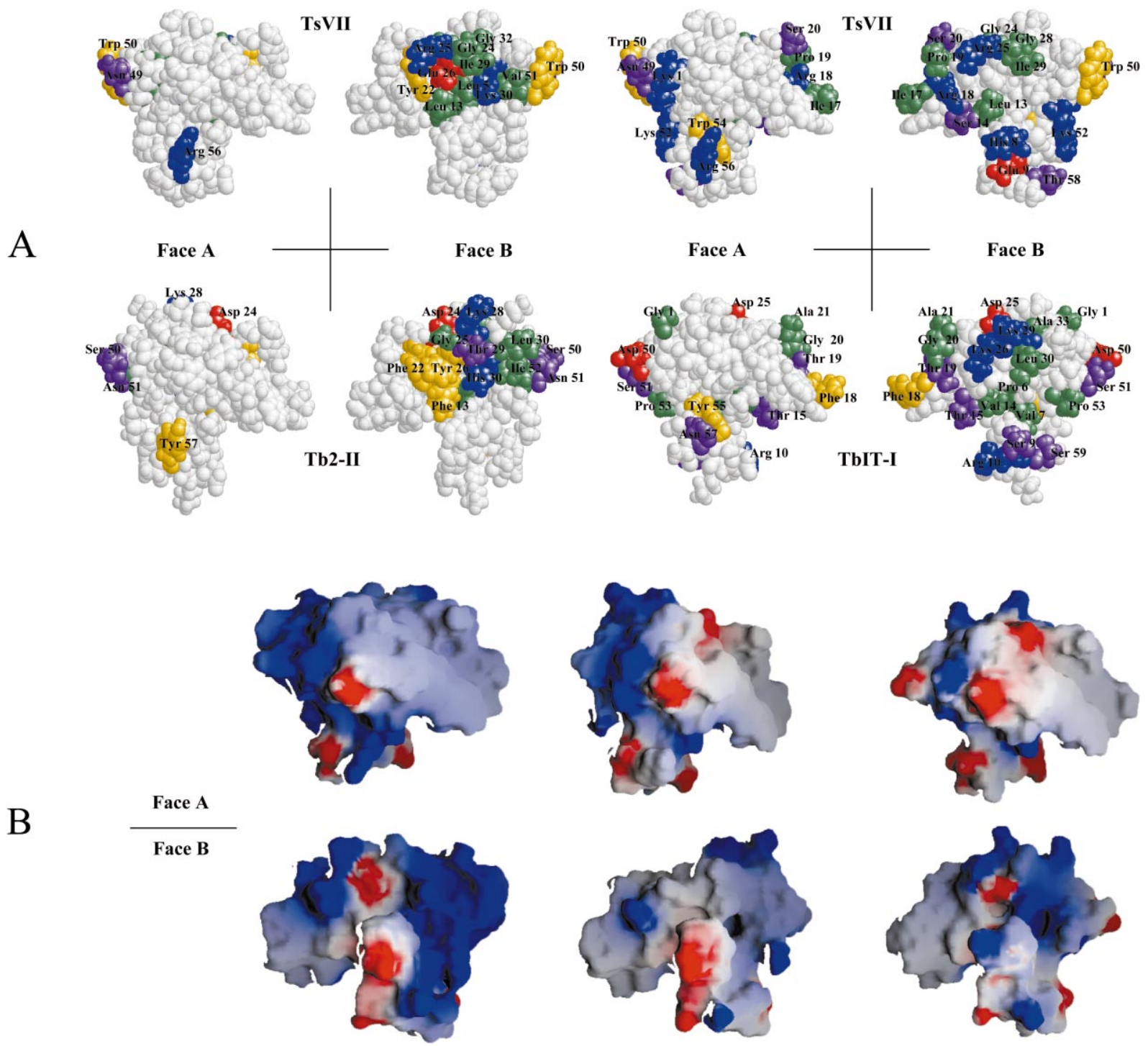

TsVII
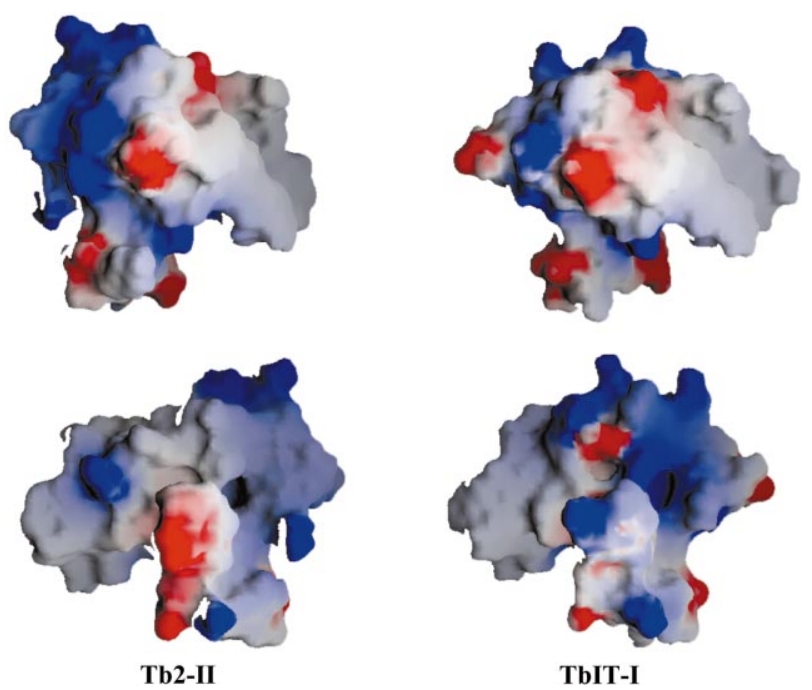

Fig. 5. Comparison of structure and electrostatic surface protperties between TsVII and the TbIT-I and Tb2-II models. A: Differences in aminoacid residues over the toxin surface. Residues are colored according to their properties: positively charged, blue; negatively charged, red; uncharged, purple; aromatic, yellow; hydrophobic, green. Consensus residues between molecules are in white. B: The electrostatic potential of toxin surfaces is shown as a gradient of color from blue $(+\mathrm{kT} / \mathrm{e})$ to red $(-\mathrm{kT} / \mathrm{e})$. The TsVII (or Ts1) structure is from the Brookhaven Protein Data Bank (accession code 1b7d - Polikarpov et al., 1999). TbIT-I and Tb2-II models were generated as described in Materials and Methods. The electrostatic potential of surfaces was calculated using GRASP (Nicholls et al., 1991). The molecules are shown in the same orientation as proposed by Polikarpov et al. (1999).

shown to be important for TsVII binding in both mammal and insect preparations (Hassani et al., 1999), although they are also present in TsII (Mansuelle et al., 1992), which is not toxic to insects (De Lima et al., 1986) and in the nontoxic proteins TsNTxP (Chavez-Olórtegui et al., 1996) and TsTX-VI (Marangoni et al., 1990) (Fig. 4). W54, in the TsVII sequence, is replaced by another aromatic residue,Y55, in TbIT-I (Figs. 4 and 5(A)).
W50, which has been shown not to be essential for the biological activity of TsVII (Hassani et al., 1999), is in the one of the most variable positions in all $\beta$-type toxins (Fig. 4). Although some crucial residues are thought to be in conservative regions, the changes in nonconservative regions may be responsible, at least in part, for the differences in the toxicological effects of the proteins. The crystallographic structure of TsVII and the other toxin 
models show that W50, and residues in the equivalent position in other toxins, are very exposed at the surface of the molecule (Fig. 5(A)).

Residue R56 is found only in TsVII, Tst1 and Tb1. It is replaced by Y57 in TsII (Mansuelle et al., 1992) and Tb2-II, by S57 in TsNTxP (Chavez-Olórtegui et al., 1996) and TsTX-VI (Marangoni et al., 1990) and by N57 in TbIT-I (Figs. 4 and 5(A)). This may be one of the most important differences between TsVII and the other toxins.

\subsection{Differences in electrostatical surfaces}

The basic residues of TsVII cover large areas of the surface of the molecule and their charges are thought to be involved in recognition and the modulation of binding events (Polikarpov et al., 1999).

The charges calculated for the TbIT-I and Tb2-II models were compared with those for the TsVII model (Polikarpov et al., 1999). In TsVII, the net charge was +4 , more positive than the +2 of both TbIT-I and Tb2-II. This difference in overall charge may be responsible for the lower affinity of these toxins for the rat brain sodium channel. Large differences in charge distribution all over the surfaces were observed (Fig. 5(B)).

The positive surface observed in the left side of face $A$ in TsVII (using the terminology adopted by Polikarpov et al., 1999) is completely disrupted in TbIT-I, by the insertion of G1 and the negative residue, D50. A negative spot is also observed in the region corresponding to residue D25 in this face of TbIT-I, which helps to maintain a neutral charge over the right side of the surface (Fig. 5(B)). In face B, the positive charge is disrupted in TbIT-I due to the absence of the positively charged residues, R18 and K52, found in TsVII. However, the replacement of the negatively charged residue, D9, of TsVII, by the positively charged residue, $\mathrm{R} 10$, in TbIT-I, increases the positive charge of the region and may therefore be responsible for the absence of toxicity in mammals of TbIT-I (Fig. 5(B)). A positively charged residue, $\mathrm{K} 10$, is also found in TsNTxP (Chavez-Olórtegui et al., 1996) and TsTX-VI (Marangoni et al., 1990) (Fig. 4).

Tb2-II has fewer surface differences from TsVII than does TbIT-I, consistent with its toxicological properties. The positive region, at the left part of face $\mathrm{A}$, in Tb2-II, is little disrupted by the absence of R56 (which is present in TsVII) whereas the presence of D24 decreases the positive charge in the righthand region of the same face. In the TsII model (data not shown), the positive charge is disrupted by the presence of D50, which is probably one of the major differences between TsII and TbS7. The replacement of the charged residues R25 and D26, present in face B of TsVII, by G25 and Y26 in TbS7, renders this region uncharged. The K30K31 segment in TsVII results in a much stronger positive charge in the upper part of face B. In the equivalent regions of Tb2-II, the presence of a hydrophobic residue, L31, disrupts the positive charge of this region (Figs. 4 and 5).

\section{Conclusions}

The isolation from $T$. bahiensis of two new toxins with anti-insect activity is reported in this paper. Despite their highly conserved 3D-structures, the Tityus spp $\beta$ or $\beta$-like toxins display large differences in species selectivity and degree of toxicity. These differences may be accounted for, at least partially, by differences in the electrostatic potential of surfaces. The overall charge distribution of the surface of the molecule seems to be one of the fundamental elements of toxin/target interaction. In this study, we attempted to characterize the structural elements of the interaction surface between the toxins and site 4 of the voltage-gated $\mathrm{Na}^{+}$channel.

It is known that the interaction site is located in domain II of the $\alpha$-subunit (Marcotte et al., 1997), in the S3-S4 segment of this domain (Cestèle et al., 1998). Other recent studies have shown that Musca-kdr and super-kdr, mutant strains of house flies ( $M$. domestica), with single or double mutations in domain II of the paragene encoding the voltage-gated $\mathrm{Na}^{+}$channel, are more susceptible than the wild type to the very selective contraturant toxin AaIT (Androctonus australis anti-insect toxin) (Zlotkin et al., 1999). So, it is clear that $\alpha$-toxins and anti-insect toxins, which share the same contraturant binding site, recognize extracellular peptide segments of domain II.

Negatively charged residues of the S3-S4 segment in domain IV of the voltage-gated $\mathrm{Na}^{+}$channel $\alpha$-subunit have been found to be involved in the interaction with $\alpha$ scorpion toxins. Thus, a positive electrostatic potential at the surface of the toxin, rather than the chain or its backbone, appears to play a major role in amino-acid recognition, determining selectivity for insects or mammals. However, it is possible that these complex interactions result from biphasic events. A recognition phase, which might involve a specific electrostatic interaction followed by a stronger interaction that is probably hydrophobic.

The TbIT-I and Tb2-II electrostatic models indicate clearly that the availability of charged residues varies over the surface of these molecules.

\section{Acknowledgements}

We greatly thank S. Canarelli, Julio C. Reis e Zulema J. Oliveira for technical assistence, P. Mansuelle for Sequencer and MALDI-TOF assistence and E. Feyfant for his kind help in molecular modeling. This work was supported by grants from CAPES, CAPES-COFECUB, CNPq and FAPEMIG

\section{References}

Becerril, B., Corona, M., Coronas, F.I., Zamudio, F., CalderonAranda, E.S., Fletcher Jr, P.L., Martin, B.M., Possani, L.D., 
1996. Toxic peptides and genes encoding toxin gamma of the Brazilian scorpions Tityus bahiensis and Tityus stigmurus. Biochem. J. 313 (Pt 3), 753-760.

Becerril, B., Marangoni, S., Possani, L.D., 1997. Toxins and genes isolated from scorpions of the genus Tityus. Toxicon 35 (6), 821-835.

Bechis, G., Sampieri, F., Yuan, P.M., Brando, T., Martin, M.F., Diniz, C.R., Rochat, H., 1984. Amino acid sequence of toxin VII, a beta-toxin from the venom of the scorpion Tityus serrulatus. Biochem. Biophys. Res. Commun. 122 (3), 1146-1153.

Céard, B., De Lima, M.E., Bougis, P.E., Martin-Eauclaire, M.F., 1992. Purification of the main beta-toxin from Tityus serrulatus scorpion venom using high-performance liquid chromatography. Toxicon 30 (1), 105-110.

Cestèle, S., Qu, Y., Rogers, J.C., Rochat, H., Scheuer, T., Catterall, W.A., 1998. Voltage sensor-trapping: enhanced activation of sodium channels by beta-scorpion toxin bound to the S3-S4 loop in domain II. Neuron 21 (4), 919-931.

Chavez-Olórtegui, C., Amara, D.A., Rochat, H., Diniz, C.R., Granier, C., 1991. In vivo protection against scorpion toxins by liposomal immunization. Vaccine 9 (12), 907-910.

Chavez-Olórtegui, C., Ferreira, A.M.B., Cordeiro, M.N., Maria, W.S., Richardson, M., Diniz, C.R., 1996. Envenomings and their treatment. In: Bon, C., Goyffon, M. (Eds.), Proceedings of the First International Congress, Institute Pasteur, Paris, 7-9 June, pp.183-195.

Chavez-Olórtegui, C., Kalapothakis, E., Ferreira, A.M.B.M., Ferreira, A.P., Diniz, C.R., 1997. Neutralizing capacity of antibodies elicited by a non-toxic protein purified from the venom of the scorpion Tityus serrulatus. Toxicon 35 (2), 213-221.

Chettibi, S., Lawrence, A., 1989. High resolution of honey bee (Apis mellifera) venom peptides by propionic acid/urea polyacrylamide gel electrophoresis after ethanol precipitation. Toxicon 27 (7), 781-787.

De Lima, M.E., Martin, M.F., Diniz, C.R., Rochat, H., 1986. Tityus serrulatus toxin VII bears pharmacological properties of both $\beta$ toxin and insect toxin from scorpion venoms. Biochem. Biophys. Res. Commun. 139 (1), 296-302.

De Lima, M.E., Martin-Eauclaire, M.F., 1995. The toxins purified from Tityus serrulatus (Lutz \& Mello) venom. J. Toxicol.Toxin Reviews 14 (3), 457-481.

Friedman, M., Krull, L.H., Cavins, J.F., 1970. The chromatographic determination of cystine and cysteine residues in proteins as sbeta-(4-pyridylethyl)cysteine. J. Biol. Chem. 245 (15), $3868-$ 3871.

Gordon, D., Martin-Eauclaire, M.F., Cestèle, S., Kopeyan, C., Carlier, E., Khalifa, R.B., Pelhate, M., Rochat, H., 1996. Scorpion toxins affecting sodium current inactivation bind to distinct homologous receptor sites on rat brain and insect sodium channels. J. Biol. Chem. 271 (14), 8034-8045.

Hammock, B.D., McCutchen, B.F., Beetham, J., Choudary, P.V., Fowler, E., Ichinose, R., Ward, V.K., Vickers, J.M., Bonning, B.C., Harshman, L.G., et al., 1993. Development of recombinant viral insecticides by expression of an insect-specific toxin and insect-specific enzyme in nuclear polyhedrosis viruses. Arch. Insect. Biochem. Physiol. 22 (3-4), 315-344.

Hassani, O., Mansuelle, P., Cestèle, S., Bourdeaux, M., Rochat, H., Sampieri, F., 1999. Role of lysine and tryptophan residues in the biological activity of toxin VII (Ts $\gamma$ ) from scorpion Tityus serrulatus. Eur. J. Biochem. 260 (1), 76-78.

Jablonsky, M.J., Jackson, P.L., Trent, J.O., Watt, D.D., Krishna,
N.R., 1999. Solution structure of a beta-neurotoxin from the New World scorpion Centruroides sculpturatus Ewing. Biochem. Biophys. Res. Commun. 254 (2), 406-412.

Kalapothakis, E., Chavez-Olórtegui, C., 1997. Venom variability among several Tityus serrulatus specimens. Toxicon 35 (10), 1523-1529.

Laskowski, R.A., MacArthur, M.W., Moss, D.S., Thornton, J.M., 1993. PROCHECK: a program to check the stereochemical quality of protein structures. J. Appl. Cryst. 26, 283-291.

Lebreton, F., Delepierre, M., Ramirez, A.N., Balderas, C., Possani, L., 1994. Primary and NMR three-dimensional structure determination of a novel crustacean toxin from the venom of the scorpion Centruroides limpidus limpidus Karsch. Biochemistry 33 (37), 11135-11149.

Lourenço, W.R., Cloudsley-Thompson, J.L., Cuellar, O., Von Eickstedt, V.R.D., Barraviera, B., Knox, M.B., 1996. The evolution of scorpionism in Brazil in recent years. J. Venom. Anim. Toxins 2 (2), 121-134.

Maeda, S., Volrath, S.L., Hanzlik, T.N., Harper, S.A., Majima, K., Maddox, D.W., Hammock, B.D., Fowler, E., 1991. Insecticidal effects of an insect-specific neurotoxin expressed by a recombinant baculovirus. Virology 184 (2), 777-780.

Mansuelle, P., Martin-Eauclaire, M.F., Chavez-Olórtegui, C., De Lima, M.E., Rochat, H., Granier, C., 1992. The beta-type toxin Ts II from the scorpion Tityus serrulatus: amino-acid sequence determination and assessment of biological and antigenic properties. Nat. Toxins 1 (2), 119-125.

Marangoni, S., Ghiso, J., Sampaio, S.V., Arantes, E.C., Giglio, J.R., Oliveira, B., Frangione, B., 1990. The complete amino acid sequence of toxin TsTx-VI isolated from the venom of the scorpion Tityus serrulatus. J. Protein Chem. 9 (5), 595601.

Marangoni, S., Toyama, M.H., Arantes, E.C., Giglio, J.R., da Silva, C.A., Carneiro, E.M., Goncalves, A.A., Oliveira, B., 1995. Amino-acid sequence of TsTX-V, an alpha-toxin from Tityus serrulatus scorpion venom, and its effect on $\mathrm{K}^{+}$permeability of beta-cells from isolated rat islets of Langerhans. Biochim. Biophys. Acta 1243 (3), 309-314.

Marcotte, P., Chen, L.Q., Kallen, R.G., Chahine, M., 1997. Effects of Tityus serrulatus scorpion toxin gamma on voltage-gated $\mathrm{Na}^{+}$channels. Circ. Res. 80 (3), 363-369.

Martin-Eauclaire, M.F., Céard, B., Ribeiro, A.M., Diniz, C.R., Rochat, H., Bougis, P.E., 1992. Molecular cloning and nucleotide sequence analysis of a cDNA encoding the main betaneurotoxin from the venom of the South American scorpion Tityus serrulatus. FEBS Lett. 302 (3), 220-222.

Martin-Eauclaire, M.F., Ceard, B., Ribeiro, A.M., Diniz, C.R., Rochat, H., Bougis, P.E., 1994. Biochemical, pharmacological and genomic characterisation of Ts IV, an alpha-toxin from the venom of the South American scorpion Tityus serrulatus. FEBS Lett. 342 (2), 181-184.

McCutchen, B.F., Choudary, P.V., Crenshaw, R., Maddox, D., Kamita, S.G., Palekar, N., Volrath, S., Fowler, E., Hammock, B.D., Maeda, S., 1991. Development of a recombinant baculovirus expressing an insect-selective neurotoxin: potential for pest control. Biotechnology 9 (9), 848-852.

Nicholls, A., Sharp, K.A., Honig, B., 1991. Protein folding and association: insights from the interfacial and thermodynamic properties of hydrocarbons. Proteins 11 (4), 281-296.

Pintar, A., Possani, L.D., Delepierre, M., 1999. Solution structure of toxin 2 from Centruroides noxius Hoffmann, a beta-scorpion 
neurotoxin acting on sodium channels. J. Mol. Biol. 287 (2), 359-367.

Polikarpov, I., Junior, M.S., Marangoni, S., Toyama, M.H., Teplyakov, A., 1999. Crystal structure of neurotoxin Ts1 from Tityus serrulatus provides insights into the specificity and toxicity of scorpion toxins. J. Mol. Biol. 290 (1), 175-184.

Possani, L.D., Alagon, A.C., Fletcher Jr, P.L., Erickson, B.W., 1977. Purification and properties of mammalian toxins from the venom of Brazilian scorpion Tityus serrulatus (Lutz and Mello). Arch. Biochem. Biophys. 180 (2), 394-403.

Possani, L.D., Martin, B.M., Mochca-Morales, J., Svendsen, I., 1981. Purification and chemical characterization of the major toxins from the venom of the Brazilian scorpion Tityus serrulatus (Lutz and Mello). Carlsberg Research Communications 46, 195-205.

Possani, L.D., Martin, B.M., Svendsen, I., Rode, G.S., Erickson, B.W., 1985. Scorpion toxins from Centruroides noxius and Tityus serrulatus. Primary structures and sequence comparison by metric analysis. Biochem. J. 229 (3), 739-750.

Possani, L.D., Martin, B.M., Fletcher, M.D., Fletcher Jr, P.L., 1991. Discharge effect on pancreatic exocrine secretion produced by toxins purified from Tityus serrulatus scorpion venom. J. Biol. Chem. 266 (5), 3178-3185.

Rezende Jr, L., Cordeiro, M.N., Oliveira, E.B., Diniz, C.R., 1991. Isolation of neurotoxic peptides from the venom of the 'armed' spider Phoneutria nigriventer. Toxicon 29 (10), 1225-1233.

Sali, A., Blundell, T.L., 1993. Comparative protein modelling by satisfaction of spatial restraints. J. Mol. Biol. 234 (3), 779-815.

Schagger, H., Von Jagow, G., 1987. Tricine-sodium dodecyl sulfate-polyacrylamide gel electrophoresis for the separation of proteins in the range from 1 to $100 \mathrm{kDa}$. Anal. Biochem. 166 (2), 368-379.

Selisko, B., Garcia, C., Becerril, B., Delepierre, M., Possani, L.D., 1996. An insect-specific toxin from Centruroides noxius Hoffmann. cDNA, primary structure, three-dimensional model and electrostatic surface potentials in comparison with other toxin variants. Eur. J. Biochem. 242 (2), 235-242.

Stewart, L.M., Hirst, M., Lopez Ferber, M., Merryweather, A.T., Cayley, P.J., Possee, R.D., 1991. Construction of an improved baculovirus insecticide containing an insect-specific toxin gene. Nature 352 (6330), 85-88.

Tomalski, M.D., Miller, L.K., 1991. Insect paralysis by baculovirusmediated expression of a mite neurotoxin gene. Nature 352 (6330), 82-85.

Von Eickstedt, V.R.D., Ribeiro, L.A., Candido, D.M., Albuquerque, M.J., Jorge, M.T., 1996. Evolution of scorpionism by Tityus bahiensis (Perty) and Tityus serrulatus (Lutz and Mello) and geographical distribution of the two species in the State of São Paulo, Brazil. J. Venom. Anim. Toxins 2 (2), 95-105.

Zilberberg, N., Froy, O., Loret, E., Cestèle, S., Arad, D., Gordon, D., Gurevitz, M., 1997. Identification of structural elements of a scorpion alpha-neurotoxin important for receptor site recognition. J. Biol. Chem. 272 (23), 14810-14816.

Zlotkin, E., Devonshire, A.L., Warmke, J.W., 1999. The pharmacological flexibility of the insect voltage gated sodium channel: toxicity of AaIT to knockdown resistant (kdr) flies. Insect Biochem. Mol. Biol. 29 (10), 849-853. 